\title{
Jean Talairach: a cerebral cartographer
}

\author{
Maya Harary, MD, ${ }^{2}$ and G. Rees Cosgrove, MD, FRCSC ${ }^{1,2}$ \\ ${ }^{1}$ Harvard Medical School and 2Department of Neurosurgery, Brigham and Women's Hospital, Boston, Massachusetts
}

Although French psychiatrist-turned-neurosurgeon Jean Talairach (1911-2007) is perhaps best known for the stereotaxic atlas he produced with Pierre Tournoux and Gábor Szikla, he has left his mark on most aspects of modern stereotactic and functional neurosurgery. In the field of psychosurgery, he expressed critique of the practice of prefrontal lobotomy and subsequently was the first to describe the more selective approach using stereotactic bilateral anterior capsulotomy. Turning his attention to stereotaxy, Talairach spearheaded the team at Hôpital Sainte-Anne in the construction of novel stereotaxic apparatus. Cadaveric investigation using these tools and methods resulted in the first human stereotaxic atlas where the use of the anterior and posterior commissures as intracranial reference points was established. This work revolutionized the approach to cerebral localization as well as leading to the development of numerous novel stereotactic interventions by the Sainte-Anne team, including tumor biopsy, interstitial irradiation, thermal ablation, and endonasal procedures. Together with epileptologist Jean Bancaud, Talairach invented the field of stereo-electroencephalography and developed a robust scientific methodology for the assessment and treatment of epilepsy. In this article the authors review Talairach's career trajectory in its historical context and in view of its impact on modern stereotactic and functional neurosurgery.

https://thejns.org/doi/abs/10.3171/2019.6.FOCUS19320

KEYWORDS Jean Talairach; stereotaxy; cerebral localization; psychosurgery; epilepsy surgery; neurosurgical history

$\mathbf{J}$ EAN Talairach was born in 1911 in Perpignan, on the French-Spanish border (Fig. 1). As a youth, he was immersed in music and developed a passion for architecture, often exploring abandoned mines and drawing architectural building plans. ${ }^{20,22}$ Perhaps to follow in the footsteps of his cousin (psychiatrist Henri Ey), or perhaps due to the inspiring historic halls of the Faculty of Medicine at Montpellier, Talairach decided to pursue a career in medicine ${ }^{33}$ After finishing his undergraduate medical training in 1938, he moved to Paris for training in psychiatry at Hôpital Sainte-Anne under renowned psychiatrist Jean Delay. ${ }^{4,20}$

Sainte-Anne was originally established as an asylum for the mentally ill in the 1600 s and was converted to a psychiatric hospital in the following century. ${ }^{43}$ It was right around the time Talairach arrived at the institution that the neurosurgery department was established by neurosurgeon Pierre Puech with the aim of exploring surgical treatments to psychiatric diseases. ${ }^{43}$ Although Talairach was named clinical director of the psychiatric service, a meeting in 1942 changed his career trajectory and resulted in reverberating effects on the field of neurosurgery. Neurologist Julian de Ajuriaguerra introduced Talairach to neurosurgeon Marcel David (who would later become the second chief of neurosurgery at Sainte-Anne). Talairach recounts: "I will never forget this first meeting on a Monday in April 1942 and that particular anguish, known to those who suddenly discover a world hoped for, and one that would make me irresistibly abandon my career in psychiatry that was already laid out before me." ${ }^{32}$ (Quotes in the text represent the first author's [M.H.] translation from the original French text.) He subsequently began his neurosurgical training at Hôpital Paul-Brousse under the tutelage of David.

\section{Psychosurgery}

While Talairach's name is most commonly associated with his significant contributions to the field of stereotaxy, he made his initial contributions at the intersection of his

ABBREVIATIONS AC = anterior commissure; $\mathrm{AP}=$ anteroposterior; $\mathrm{ECOG}=$ electrocorticography; $\mathrm{MNI}=\mathrm{Montreal}$ Neurological Institute; $\mathrm{OR}=$ operating room; $\mathrm{PC}=$ posterior commissure; SEEG = stereo-electroencephalography.

SUBMITTED May 1, 2019. ACCEPTED June 6, 2019.

INCLUDE WHEN CITING DOI: 10.3171/2019.6.FOCUS19320. 


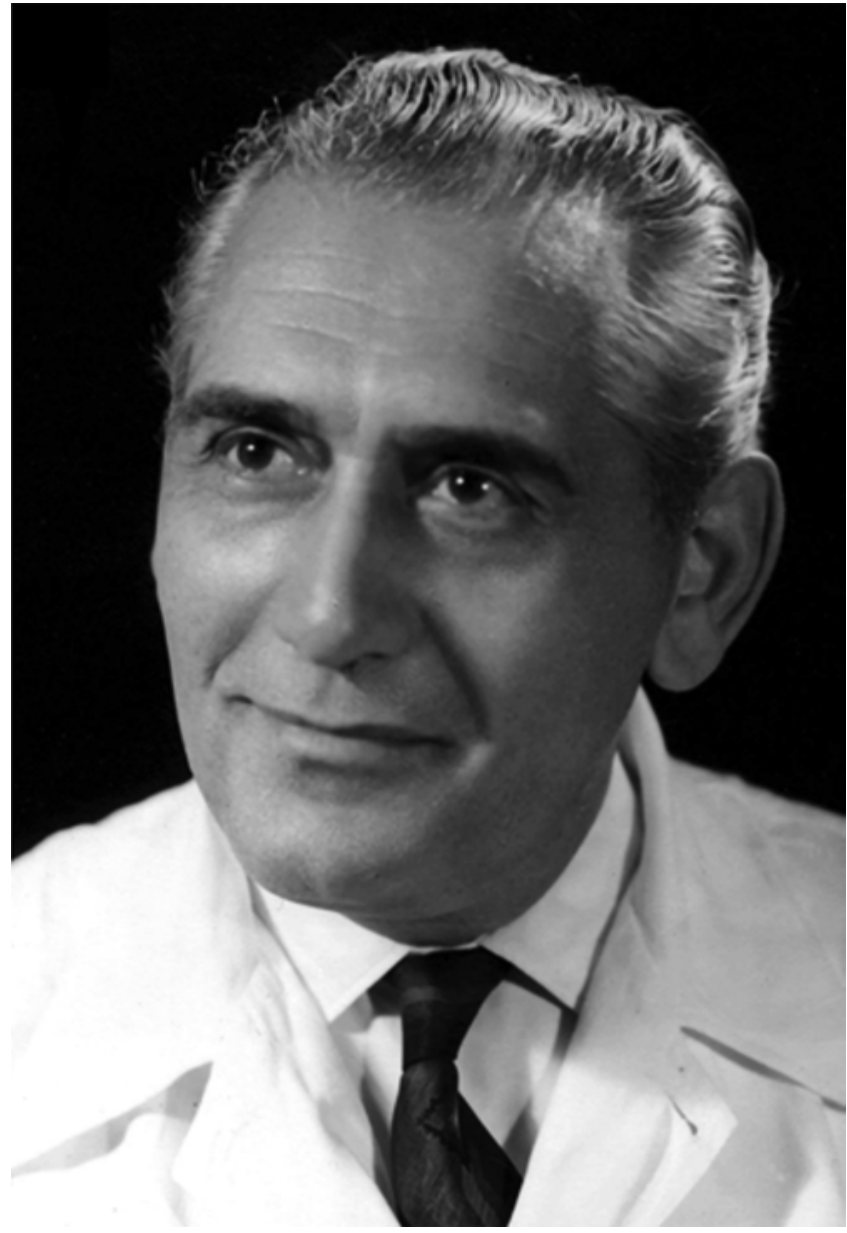

FIG. 1. Photograph of Dr. Jean Talairach. Reproduced from Bourdillon P, Apra C, Lévêque M, Vinckier F: Neuroplasticity and the brain connectome: what can Jean Talairach's reflections bring to modern psychosurgery? Neurosurg Focus 43(3):E11, 2017. Published with permission.

two paths in medicine - in the field of psychosurgery. ${ }^{43} \mathrm{Ta}-$ lairach began his career at a time when neuroleptics were not yet available and Egas Moniz's prefrontal lobectomy, first performed in 1936, was being popularized. ${ }^{21}$ Partnering with his new mentor, David, the two went on to perform numerous prefrontal lobotomies at several Paris hospitals, reporting mixed results. ${ }^{43}$

With his background in psychiatry, Talairach was critical of the technique and is in fact often quoted saying that "psychosurgery is too important to leave to the neurosurgeons."9,43 Talairach was influenced by the work of his cousin, Sainte-Anne psychiatrist Henri Ey, on the organodynamic theory which adopts the Jacksonian framework of nervous system organization and applies it to psychology. ${ }^{5}$ In the context of the sensorimotor system, Jackson described the presence of a gradual hierarchy from sensory organs and motor neurons all the way to higher centers (i.e., premotor areas and sensory association cortices); at these higher levels, function is not represented in discrete areas, as is suggested by the localizationalist theory, but rather by diffuse networks. ${ }^{16}$ Applying this theory to psychology, Ey maintained that mental illness, with complex pathologic manifestations such as hallucinations and alterations in consciousness and behavior, is a result of disturbance in higher functional centers with diffuse represention. ${ }^{13}$ With this in mind, Talairach argued that gross resection/disconnection of large portions of the network involved in the pathology (i.e., frontal lobotomy/leucotomy) may not be necessary. ${ }^{42}$ Rather, a more selective approach, targeting a single network node or network fiber tracts may be sufficient. In this vein, in 1949, Talairach first described the use of bilateral anterior capsulotomy for psychiatric disease, turning a necessary new leaf for psychosurgery. ${ }^{37}$ Ironically, that same year, Egas Moniz won the Nobel Prize in Medicine for the frontal lobotomy.

In 1952, Talairach's initial mentor, Sainte-Anne psychiatrist Jean Delay, and colleague Pierre Deniker discovered the first neuroleptic, chlorpromazine. ${ }^{10}$ The development of psychopharmacology and changes in public opinion, among other factors, led to a decline in psychosurgery, and Talairach turned his attention more fully to his work in stereotaxy and later, epilepsy surgery. ${ }^{43}$

\section{A New Stereotaxic Approach}

In the early 1900s, Horsley and Clarke developed the first stereotactic frame based on a 3D Cartesian coordinate system for animal use. ${ }^{15}$ The first human stereotactic frame was built soon thereafter by Canadian neurologist Aubrey Mussen; his contribution went largely unnoticed at the time, likely because up until the 1940s the thought of using intracerebral electrodes in the human was faced with an ethical resistance to the violation of the human brain. ${ }^{17,26,33}$ In a book published shortly after his passing, Talairach recounts the moment that he moved from the theoretical to the practical stage of stereotaxy in the human brain. ${ }^{33}$ David, Talairach, and neurologists Hécaen and De Ajuriaguerra attended a conference hosted by renowned neurologist Jean Lhermitte (of Lhermitte's sign, among others) at Hôpital Paul-Brousse. Lhermitte was presenting work on thalamic pain syndromes. "Driven by the feeling of false precision felt during interventions for abnormal movements or for mental disorders, and the discomfort felt in the trans-cerebral pursuit of some everelusive epileptogenic foci," 32 the attendants set the goal of building a device that would allow for the precise interrogation and, if necessary, ablation of deep structures in the human brain. ${ }^{27,33}$

When it came to localizing thalamic nuclei, the question, then as it is now, was how do you find something you cannot see? At the time, neuroimaging was limited to monoplanar radiography, allowing for the identification of bony cranial landmarks. This could be supplemented with the use of intraventricular and intravascular contrast agents, allowing for a delineation of the ventricular system and cerebral arterial supply. These structures could therefore be localized in a direct fashion. ${ }^{40}$ In contrast, localization of the deep gray nuclei and cerebral cortex could only be done in relation to these visible structures, in an indirect fashion. Interestingly, the term "direct localization" has taken on a somewhat different meaning in modern functional surgery; today, it most often refers to physiological localization by means of identifying stereotypical neuronal firing patterns obtained using microelectrode 


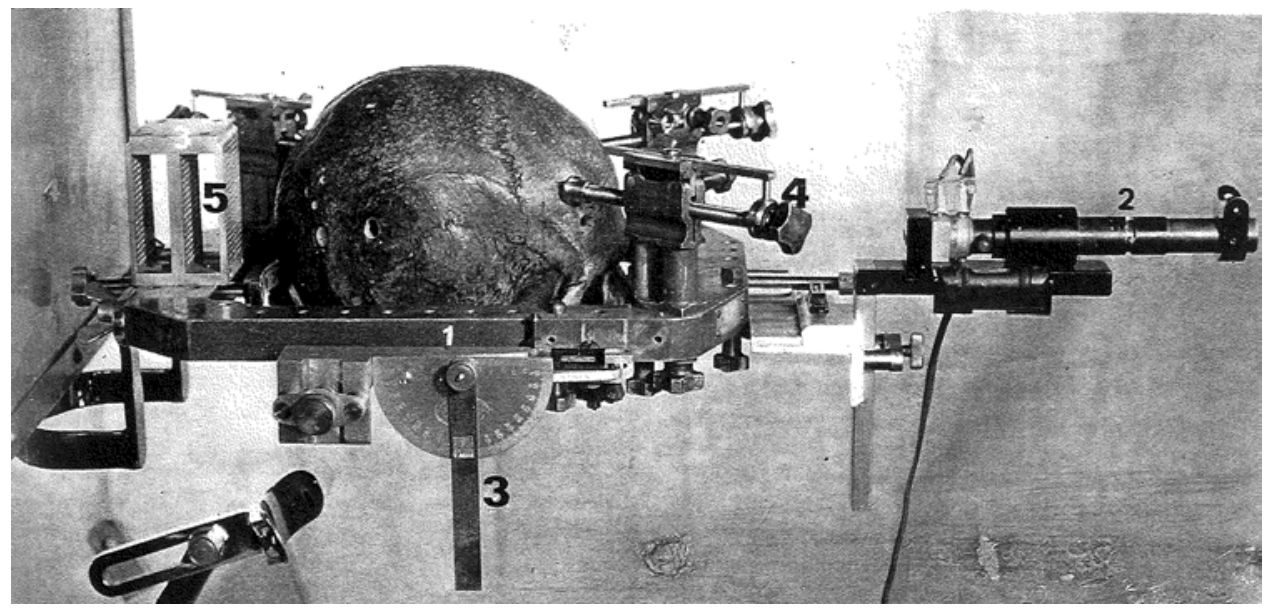

FIG. 2. Talairach stereotaxic apparatus. 1 = frame; 2 = luminous sight target for $x$-ray beam centering; $3=$ level; 4 = cranial fixation fastener; 5 = double grid. Reproduced from Talairach J: Souvenirs des Études Stéréotaxiques du Cerveau Humain. John Libbey Eurotext, 2007. Published with permission.

recording. Indirect targeting has become more granular thanks to the advances in modern neuroimaging which have made many more parenchymal structures visible.

Entrusted with developing a reliable, indirect method to localize deep gray nuclei, Talairach contracted SainteAnne's resident technician, M. Sabbaton, to help him build a suitable stereotactic frame to his specification. ${ }^{19,33}$ These efforts were mirrored by functional neurosurgeons all over the world, who began developing their own frames for human use by collaborating with local engineers; Talairach in France, Leksell in Sweden, Mundinger in Germany, Narabayashi in Japan, Bertrand in Canada, and Roberts in the United States all developed their own prototypes. While Spiegel and Wycis have long been credited with the first human stereotactic frame, much controversy exists over who actually "invented" the first human stereotactic frame, and Talairach and Wycis often debated this point heatedly, almost to the point of fisticuffs (G. Bertrand, personal communication). Nevertheless, Spiegel and Wycis were indeed the first to report the use of a stereotactic frame in the human in 1947, using it to perform a thermal medial thalamotomy. ${ }^{29}$

Each feature of the Talairach frame was designed based on the understanding that the key to accurate indirect targeting was accurate and reliable imaging. A central feature of the frame was the double grid system (Fig. 2) - the grids were attached at opposite edges of the frame perpendicular to the path of the x-ray. If the image was acquired without distortion (displacement or magnification), the double grids would superimpose and appear as a single grid on the acquired image..$^{19,20,31}$ The thick grids also allowed for the stable introduction of multiple probes. ${ }^{19,20}$ Another key difference between Spiegel and Wycis' frame and the one developed at Sainte-Anne was that the Talairach frame was fixed directly to the outer table of the skull, whereas the Spiegel and Wycis frame was fixed to the head by means of a plaster cap; $;^{29,40}$ the cranial fixation of the Talairach frame allowed for accurate repositioning between imaging and/or treatment sessions, which proved particularly useful in staged surgery. Talai- rach also developed a system for collimated teleradiography to further reduce distortion and magnification, which was supplemented by the use of long-distance stereoradiology, made possible by the building of a large operating room to Talairach's specifications. ${ }^{4,19,20}$ The team first used their steereotactic apparatus in 1948 to perform a thalamotomy for the treatment of central pain syndrome. ${ }^{31}$ Over the years, the Sainte-Anne team used this apparatus for numerous stereotactic interventions, including tumor biopsy, interstitial irradiation, thermal lesioning, stereoelectroencephalography (SEEG), and endonasal procedures. ${ }^{19,32,33,35,37,39,41}$

Talairach and colleagues used their stereotactic apparatus to study 100 cadaveric brains, which in 1957 resulted in the first stereotaxic atlas of the human deep gray nuclei. ${ }^{36}$ Although the use of cranial bony landmarks was the standard in animal stereotaxic atlases, such as those used by Horsley and Clarke, bony landmarks were thought to be insufficiently reliable for human interventions-both due to the lower margin for error and due to the greater structural variability among humans than among laboratory animals. ${ }^{31}$ In lieu of bony landmarks, or the calcified pineal and foramen of Monro used by Spiegel and Wycis, Talairach introduced the anterior commissure (AC) and posterior commissure (PC) as the standard points of references, which were selected because they could be reliably identified on contrast ventriculography and were in close proximity to the deep gray nuclei. ${ }^{20,31}$ The newly established Talairach coordinate space was therefore defined by an origin at the AC, a y-axis along the AC-PC line, and $\mathrm{a}$ X-axis and a $\mathrm{z}$-axis extending perpendicularly from AC along the horizontal and vertical planes, respectively (Fig. 3 upper). In 1958, Talairach became head of the newly founded stereotaxic and functional neurosurgical service at Sainte-Anne and continued his work, now with Hungarian-born neurosurgeon Gábor Szikla, to generate a second atlas focusing on the telencephalon. ${ }^{38}$ In 1988, a third atlas was published, by Talairach and Tournoux, which covered the whole human brain. Recognizing the neuroanatomical variability between patients, they devel- 


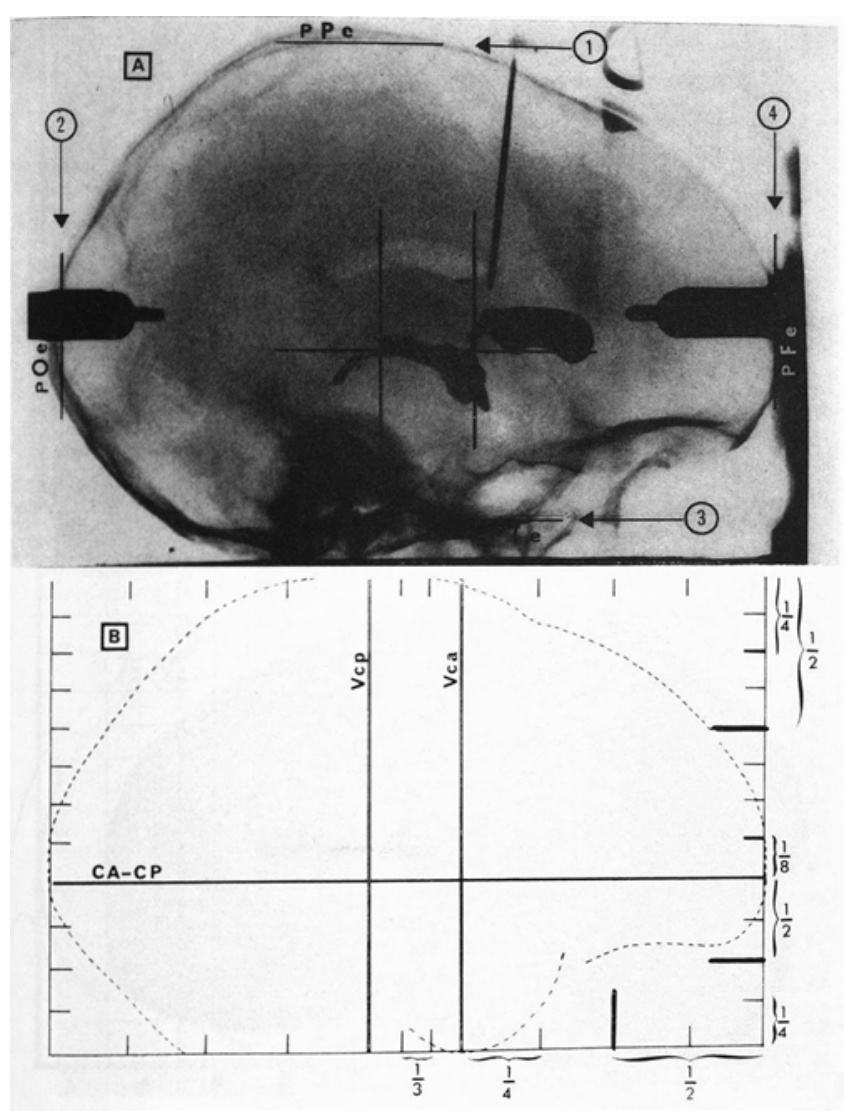

FIG. 3. Upper: Contrast ventriculogram showing the $A C$ and $P C$ lines of references. Lower: Proportional grid system. Vca and $V_{c p}$ indicate vertical lines projecting superiorly from the AC and PC, respectively. Reproduced from Talairach J, Bancaud J; Stereotaxic approach to epilepsy. In Krayenbühl H, Maspes PE, Sweet WH (eds): Progress in Neurological Surgery. Karger: Basel, 1973. Copyright @ 1973 Karger Publishers, Basel, Switzerland. Published with permission.

oped a proportional grid system (Fig. 3 lower) that allowed for the transformation of any point in the Talairach space to patient-specific coordinates and vice-versa. ${ }^{40}$ Talairach viewed the development of the proportional grid system as a necessary component of a complete stereotaxic system for two main reasons. First, it allowed for the consideration of the volume of the brain in its entirety, in contrast to stereotaxic systems that focused on the deep gray nuclei or on the temporal lobe in isolation, for example, each with their own reference point system. This holoencephalic stereotaxic system was necessary, in particular, for SEEG work. Second, the proportional grid system allowed for the stereotaxic system to go beyond the guidance of neurosurgical intervention in individuals; it provided a tool for the study of functional localization across individuals, since any individual-specific point could be abstracted to a standardized space. For his contributions to stereotaxy, Talairach was awarded in 1989 the Prix de l'État - Grand Prix des Sciences chimiques et naturelles (grand prize in chemical and natural sciences) by the Académie des Sciences. $^{33}$

The Talairach and Tournoux 1988 atlas is limited by a number of factors. Most importantly, it is based on a single postmortem brain, which limits its generalization, despite the proportional grid system. Additionally, the atlas is composed of 2D sections without a corresponding 3D representation, which, in today's digital age, limits the utility of the atlas for digital MRI analysis and functional mapping. ${ }^{7}$ In the 1990 s, Evans et al. at the Montreal Neurological Institute (MNI) described a new coordinate space which has since been adopted for many applications. ${ }^{12}$ The MNI space maintained the $\mathrm{AC}$ as the point of origin, as initially established by Talairach and colleagues in the $1950 \mathrm{~s} .{ }^{20}$ However, unlike the Talairach atlas, the MNI space is based on a pooled average of hundreds of brain MRI scans. ${ }^{8,12}$ Despite the limitations of the Talairach space, it remains the standard universal reference system, and the Talairach and Tournoux atlas remains a seminal work and fundamental tool for the stereotactic neurosurgeon.

\section{Wartime Efforts}

Talairach's arrival at Sainte-Anne at the end of the 1930s coincided with an arrival of an altogether different nature in Paris - the Nazi invasion. Initially, Talairach served at the military hospital Val-de-Grace. ${ }^{32}$ In the following years, under Nazi occupation, Talairach's friend and colleague, psychiatrist René Suttel, discovered an entrance to Paris' catacombs network south of the Seine underneath Sainte-Anne. The two were recruited by the French resistance to chart the catacombs system with the intent that it could be used for storage of munitions and supplies. ${ }^{31}$ Suttel, who had a preexisting fascination with the subterranean system, and Talairach, with his passion for architecture and a keen sense for geometry, went on nightly excursions that resulted in a meticulous map of the system (Fig. 4). ${ }^{6}$ During the day, Talairach was studying neuroanatomy and developing the founding principles that years later resulted in the stereotaxic atlas, and during the night, he was working on an altogether different kind of map. This map, detailing around $100 \mathrm{~km}$ of the subterranean tunnels, carefully noted intersections, junctions, and unique characteristics or reference points allowing for navigation. ${ }^{30}$ These maps were reportedly used to select the bunker location for resistance headquarters out of which commander Colonel Rol-Tanguy coordinated the Battle of Paris in August of 1944. ${ }^{6}$ For these efforts, Talairach and Suttel were awarded both the Croix de Guerre, France's highest military distinction, and were later also inducted into the Légion d'honneur, the highest French order of military and civic merit. ${ }^{22}$

\section{Epilepsy Surgery and Development of SEEG}

In the first half of the 20th century, Wilder Penfield and Herbert Jasper at the MNI revolutionized epilepsy surgery with their electrocorticography (ECoG)-based "Montreal method." 25 This method used surface recording to localize the seizure-onset zone based on a correlation between seizure semiology and the interictal spike patterns. ${ }^{24,25} \mathrm{Ta}-$ lairach and epileptologist Jean Bancaud were unsatisfied with the ability to unambiguously delineate the epileptogenic zone (Fig. 5), which they defined as the beginning site of an epileptic seizure and of its primary organization, 


\section{CATACOMB NETWORK UNDER PARIS}

A hand-drawn map served the French Resistance against the city's Nazi occupation in 1943.

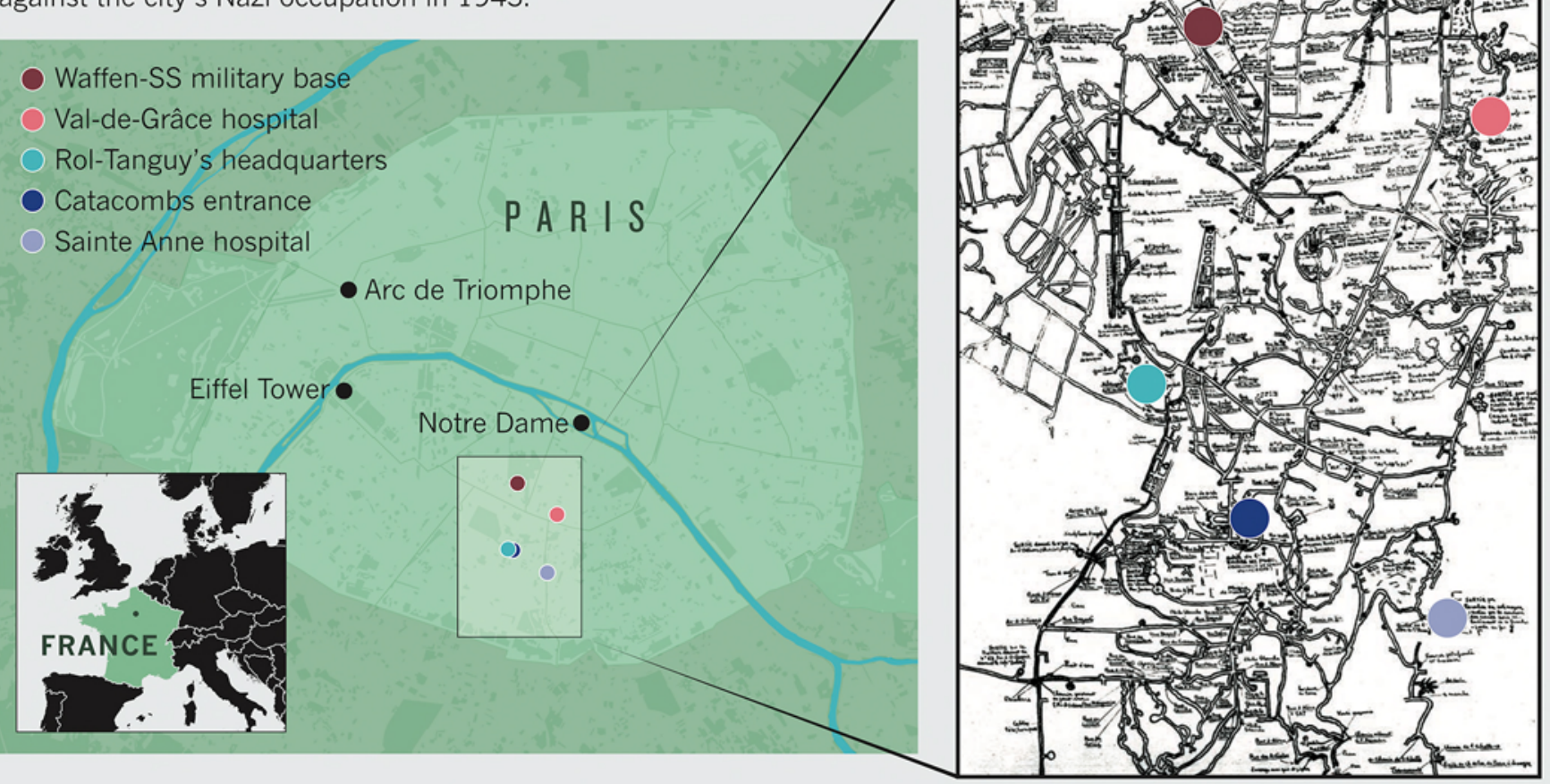

FIG. 4. Hand-drawn map of Paris catacombs produced by Talairach and Suttel. Reprinted by permission from Springer Nature Customer Service Centre GmbH: Springer Nature. Nature 547:281. Second World War: Paris neurosurgeon's map outwitted Nazis; Bourdillon P, Lévêque M, Apra C: @ 2017. https://www.nature.com.

using interictal ECoG alone, particularly in patients without a macroscopically visible epileptogenic lesion or with insular epilepsy. ${ }^{18,24,32}$ They emphasized the importance of understanding not only where epileptic seizure activity originated but also its pattern of propagation in surrounding tissue, as well as identifying when and where it eventually results in clinical symptoms. . $^{1,234,35} \mathrm{~A}$ characterization of the epileptic network enables cortical excision of epileptogenic tissue, when appropriate and safe, and/ or disconnection of critical propagation pathways..$^{35}$ This dynamic physiological description of an epileptic seizure required ictal recordings in awake patients, with multiple accurately and safely placed multi-lead intracerebral electrodes-something that Talairach's stereotaxic method made possible.

The "Sainte-Anne method" developed by Talairach and Bancaud consisted of 2 stages-reconnaissance and SEEG exploration-with the purpose of generating an anatomo-electro-clinical correlation. ${ }^{1,34,33}$ In stage I, the patients would undergo a thorough clinical examination with a detailed assessment of seizure semiology as well as scalp EEG (Fig. 6). They would then be fitted with the stereotactic frame and undergo a series of anteroposterior (AP) and lateral imaging in the specialized stereotaxic operating room (OR), including fractionated encephalography, ventriculography, and arteriography. All images were developed on semitransparent paper which noted the frame's reference points, allowing for the transfer of information onto two, to-scale master tracings (AP and lateral).$^{19}$ Applying the principles of direct and indirect lo- calization and the proportional grid system, the patient's anatomy was mapped onto the tracings. This anatomy was then assessed by the multidisciplinary team in the context of the patient's seizure semiology and EEG recordings in order to design a patient-specific, hypothesis-driven SEEG lead placement plan that took safety into account (avoiding cerebral arteries shown on the arteriogram). ${ }^{35}$

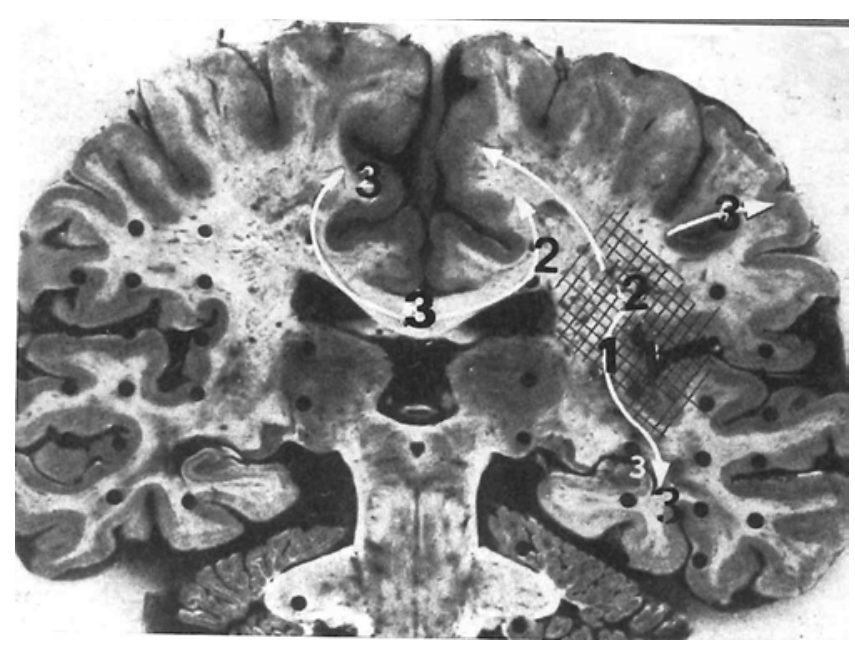

FIG. 5. Zones in epilepsy surgery: 1 = epileptogenic zone; 2 = irritative zone; 3 = paths of seizure spread. Reproduced from Talairach J: Souvenirs des Études Stéréotaxiques du Cerveau Humain. John Libbey Eurotext, 2007. Published with permission. 

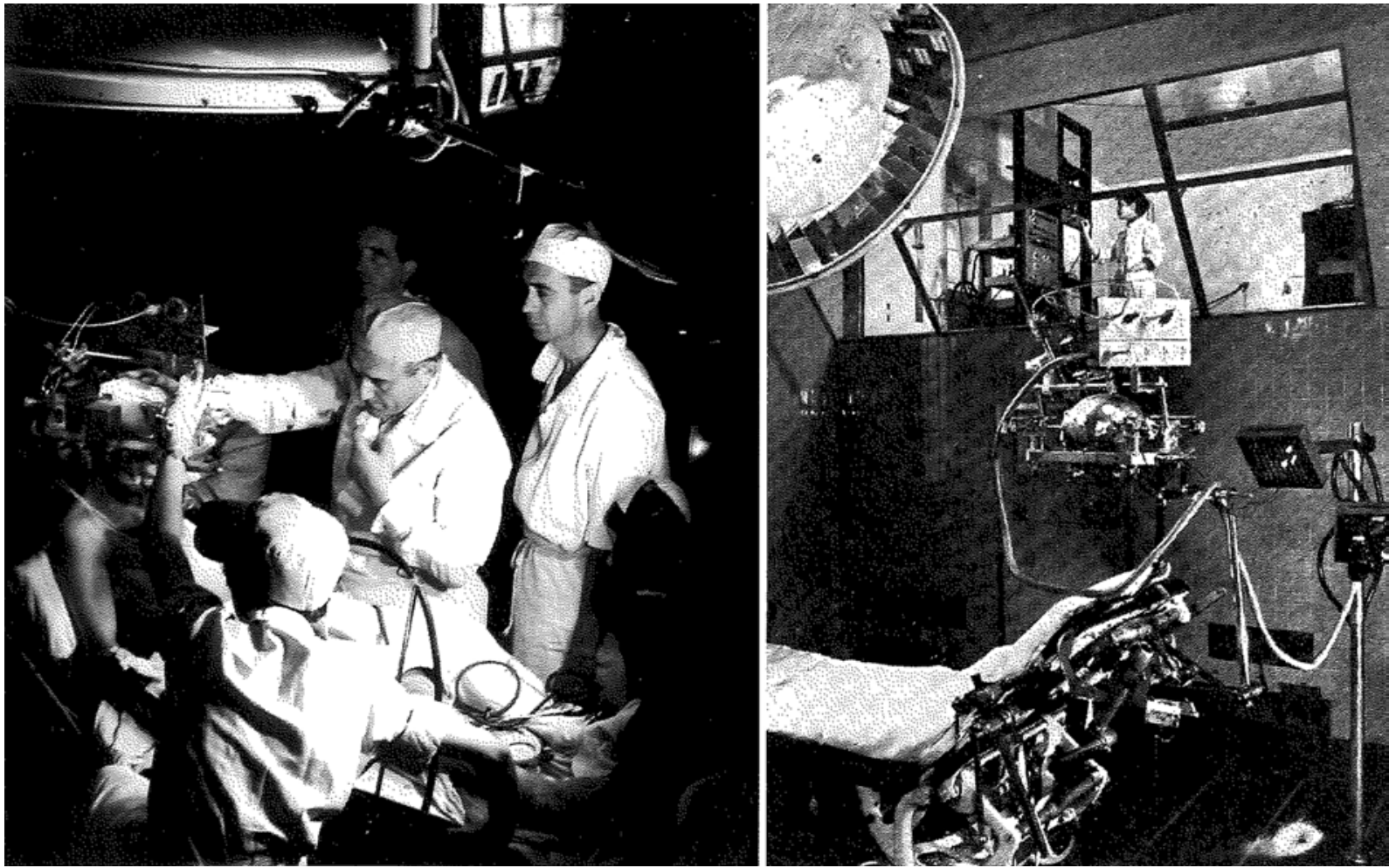

FIG. 6. Epilepsy surgery at Sainte-Anne. Left: Talairach in the operating room during an epilepsy case. Right: Operating room with overlooking room for SEEG, built after the MNI model. Reproduced from Talairach J: Souvenirs des Études Stéréotaxiques du Cerveau Humain. John Libbey Eurotext, 2007. Published with permission.

Stage II, which typically was done about 15 days after stage I, started with replacement of the stereotactic apparatus with verification of exact same location as prior. ${ }^{33,35}$ SEEG multilead depth electrodes were then placed according to the presurgical plan and their position was verified. Then came the time to wait for the occurrence of a seizure in the awake patient. Of this period, Talairach recounts: "This waiting requires a lot of patience, but remarkably, the patient, aware of the physicians' effort to subdue a disease which is often frightening for the patient, remains not only patient but also contributes to the research. It is equally remarkable to see patients share in the physicians' joy when they are able to elicit a seizure, indicating that they are reaching their goal and that a corticectomy may be done successfully, and that they may together overcome the disease." ${ }^{33}$ Although acute recordings were the rule at that time, chronic recordings (i.e., with the electrodes left in place) were also done occasionally. ${ }^{35}$ The acute recordings were limited by their short EEG recording time span (6-12 hours) and often interictal activity alone or a single seizure. Once the electrodes were implanted, the surgical team would often retreat to the OR lounge to await a seizure over wine and cheese. The patient's file, with all collected data, would be evaluated by the team to construct said anatomo-electro-clinical correlation, at which point a therapeutic intervention may be decided upon. In the first 42 patients assessed with this methodology, Talairach and Tournoux reported no surgical complications (which was a significant a priori concern, given this was the first such report on the use of numerous electrodes) and $79 \%$ recov- ery/improvement rate in the 34 patients who were offered definitive surgical treatment based on the stereotactic interrogation. ${ }^{35}$ The Sainte-Anne team went on to assess and treat hundreds of epilepsy patients utilizing this methodology in the decades that followed. ${ }^{3}$ Although advances in neuroimaging and digital surgical planning may have significantly changed how stage I is carried out, the principles that underlie Talairach and Bancaud's methodology were carried on by their students and remain central to modern day epilepsy surgery., ${ }^{4,11,14,19}$ Mark Rayport-one of Penfield's last residents-came to Sainte-Anne in the late 1960 s as a visiting professor. ${ }^{28}$ Rayport would later translate the 1988 atlas into English and was one of the early adopters of SEEG in North America; working with his wife, psychiatrist Shirley Ferguson, he combined the MNI and Sainte-Anne methods, adding an emphasis on the neuropsychiatric status of the patient. ${ }^{23,40}$

\section{Legacy}

Talairach insisted on not patenting his stereotaxic apparatus, quoting the phrase "on ne s'enrichit avec la souffrance des autres" ("one must not get rich through the suffering of others"). ${ }^{33} \mathrm{He}$ embodied this phrase in every aspect of his clinical and academic career-through his generosity in time spent in the rigorous pursuit of better treatments for his patients and through his generosity in teaching the many students who came to learn the methods of the Sainte-Anne school., ${ }^{4,19,20}$ Jean Talairach retired from clinical practice in 1978 . He would continue his dedi- 
cated work in stereotaxy, publishing his third atlas in 1988 and then a fourth in 1993, until his death in 2007, leaving behind him tools, methods, and conceptual frameworks that are foundational to most aspects of modern stereotactic and functional neurosurgery.

\section{References}

1. Bancaud J: Apport de l'exploration fonctionnelle par voie stéréotaxique à la chirurgie de l'épilepsie; à propos de 8 observations. Neurochirurgie 5:55-112, 1959

2. Bancaud J, Talairach J: La Stéréoencéphalographie dans l'Épilepsie. Paris: Masson \& Cie, 1965

3. Bancaud J, Talairach J: Sémiologie clinique des crises du lobe temporal (méthodologie et investigations SEEG de 233 malades), in Crises Épileptiques et Épilepsies du Lobe Temporal, Tome II. Gentilly: Labaz, 1991

4. Benabid AL: Jean Talairach (1911-2007). Stereotact Funct Neurosurg 86:62-63, 2008

5. Bourdillon P, Apra C, Lévêque M, Vinckier F: Neuroplasticity and the brain connectome: what can Jean Talairach's reflections bring to modern psychosurgery? Neurosurg Focus 43(3):E11, 2017

6. Bourdillon P, Lévêque M, Apra C: Second World War: Paris neurosurgeon's map outwitted Nazis. Nature 547:281, 2017

7. Brett M, Johnsrude IS, Owen AM: The problem of functional localization in the human brain. Nat Rev Neurosci 3:243249, 2002

8. Chau W, McIntosh AR: The Talairach coordinate of a point in the MNI space: how to interpret it. Neuroimage 25:408 416, 2005

9. David M, Talairach J: Quelques réflexions sur les lobotomies préfrontales. Evol Psychiatr (Paris) 4:532-540, 1949

10. Delay J, Deniker P, Harl JM: [Therapeutic use in psychiatry of phenothiazine of central elective action (4560 RP).] Ann Med Psychol (Paris) 110:112-117, 1952 (French)

11. Desai A, Bekelis K, Darcey TM, Roberts DW: Surgical techniques for investigating the role of the insula in epilepsy: a review. Neurosurg Focus 32(3):E6, 2012

12. Evans AC, Collins DL, Mills SR, Brown ED, Kelly RL, Peters TM: 3D statistical neuroanatomical models from 305 MRI volumes, in 1993 IEEE Conference Record: Nuclear Science Symposium and Medical Imaging Conference. San Francisco: IEEE, 1993, pp 1813-1817 (http://ieeexplore. ieee.org/document/373602/) [Accessed July 10, 2019]

13. Evans P: Henri Ey's concepts of the organization of consciousness and its disorganization: an extension of Jacksonian theory. Brain 95:413-440, 1972

14. Ho AL, Feng AY, Kim LH, Pendharkar AV, Sussman ES, Halpern $\mathrm{CH}$, et al: Stereoelectroencephalography in children: a review. Neurosurg Focus 45(3):E7, 2018

15. Horsley V, Clarke RH: The structure and functions of the cerebellum examined by a new method. Brain 31:45-124, 1908

16. Jackson JH: The Croonian lectures on evolution and dissolution of the nervous system. BMJ 1:660-663, 1884

17. Jensen RL, Stone JL, Hayne RA: Introduction of the human Horsley-Clarke stereotactic frame. Neurosurgery 38:563567, 1996

18. Kahane P, Landré E, Minotti L, Francione S, Ryvlin P: The Bancaud and Talairach view on the epileptogenic zone: a working hypothesis. Epileptic Disord 8 (Suppl 2):S16-S26, 2006

19. Kelly PJ: Stereotactic navigation, Jean Talairach, and I. Neurosurgery 54:454-464, 2004

20. Mazoyer B: In memoriam: Jean Talairach (1911-2007): a life in stereotaxy. Hum Brain Mapp 29:250-252, 2008

21. Moniz E: Tentatives Opératoires Dans Le Traitement de Cer-Taines Psychoses. Paris: Masson, 1936

22. Nau JY: Jean Talairach. Le Monde. March 20, 2007 (https://www.lemonde.fr/disparitions/article/2007/03/20/ jean-talairach_885505_3382.html) [Accessed July 10, 2019]
23. Ojemann G: In memoriam: Mark Rayport, M.D. C.M., Ph.D., F.A.C.S. Epilepsia 44:1262-1264, 2003

24. Palmini A: The concept of the epileptogenic zone: a modern look at Penfield and Jasper's views on the role of interictal spikes. Epileptic Disord 8 (Suppl 2):S10-S15, 2006

25. Penfield W, Jasper H: Epilepsy and the Functional Anatomy of the Human Brain. Boston: Little, Brown and Company, 1954

26. Picard C, Olivier A, Bertrand G: The first human stereotaxic apparatus. The contribution of Aubrey Mussen to the field of stereotaxis. J Neurosurg 59:673-676, 1983

27. Rahman M, Murad GJA, Mocco J: Early history of the stereotactic apparatus in neurosurgery. Neurosurg Focus 27(3):E12, 2009

28. Rayport M: Appendix II: Conceptual foundations of studies of patients undergoing temporal lobe surgery for seizure control, in International Review of Neurobiology. Amsterdam: Elsevier, 2006, Vol 76, pp 123-127

29. Spiegel EA, Wycis HT, Marks M, Lee AJ: Stereotaxic apparatus for operations on the human brain. Science 106:349350, 1947

30. Suttel R: Catacombes et Carrières de Paris. SEHDACS, 1986

31. Talairach J: Jean Talairach, MD interviewed by Mark Rayport, MD. 1993 (https://www.youtube.com/watch?v=6_ Xj7NbAllU) [Accessed July 10, 2019]

32. Talairach J: Mes Travaux. 1965 (https://histoire.inserm.fr/ les-femmes-et-les-hommes/jean-talairach/(page)/3) [Accessed July 10, 2019]

33. Talairach J: Souvenirs des Études Stéréotaxiques du Cerveau Humain. Montrouge, France: John Libbey Eurotext, 2007

34. Talairach J, Bancaud J: Stereotaxic approach to epilepsy, in Krayenbühl H, Maspes PE, Sweet WH (eds): Progress in Neurological Surgery. Basel: S Karger, 1973, Vol 5, pp 297-354

35. Talairach J, Bancaud J, Bonis A, Szikla G, Tournoux P: Functional stereotaxic exploration of epilepsy. Confin Neurol 22:328-331, 1962

36. Talairach J, David M, Tournoux P, Corredor H, Kvasina T: Atlas d'Anatomie Stéréotaxique. Repérage Radiologique Indirect des Noyaux Gris Centraux des Régions Mésencephalosousoptique et Hypothalamique de l'Homme. Paris: Masson \& Cie, 1957

37. Talairach J, Hécaen H, David M: Lobotomie préfrontale limitée par électrocoagulation des fibres thalamo-frontales a leur émergence du bras antérieur de la capsule interne. Rev Neurol (Paris) 83:59, 1949

38. Talairach J, Szikla G: Atlas of Stereotaxic Anatomy of the Telencephalon. Paris: Masson \& Cie, 1967

39. Talairach J, Tournoux P: [Apparatus for hypophysial stereotaxis by nasal approach.] Neurochirurgie 1:127-131, 1955 (French)

40. Talairach J, Tournoux P: Co-Planar Stereotaxic Atlas of the Human Brain: 3-Dimensional Proportional System: An Approach to Cerebral Imaging. Stuttgart: Georg Thieme, 1988

41. Talairach J, Tournoux P, Szikla G, Bonis A, Bancaud J: [Surgical treatment of Parkinson's disease. Methodologic remarks and surgical technic.] Int J Neurol 2:76-91, 1961 (French)

42. Talairach MJ: [Anatomic-physiological reflections on psychosurgery.] Rev Neurol (Paris) 87:554-557, 1952 (French)

43. Zanello M, Pallud J, Baup N, Peeters S, Turak B, Krebs MO, et al: History of psychosurgery at Sainte-Anne Hospital, Paris, France, through translational interactions between psychiatrists and neurosurgeons. Neurosurg Focus 43(3):E9, 2017

\section{Disclosures}

The authors report no conflict of interest concerning the materials or methods used in this study or the findings specified in this paper. 


\section{Author Contributions}

Conception and design: both authors. Acquisition of data: Harary. Analysis and interpretation of data: Harary. Drafting the article: Harary. Critically revising the article: both authors. Reviewed submitted version of manuscript: both authors. Approved the final version of the manuscript on behalf of both authors: Harary. Administrative/technical/material support: Harary.

\section{Supplemental Information}

\section{Current Affiliations}

Dr. Harary: Department of Neurosurgery, David Geffen School of Medicine, University of California, Los Angeles, Los Angeles, CA.

\section{Correspondence}

Maya Harary: David Geffen School of Medicine, University of California, Los Angeles, CA. mharary@mednet.ucla.edu. 